\title{
Exploring the experience of using music and creative mark- making as a reflective tool during coaching supervision: An Interpretative Phenomenological Analysis
}

\author{
Beth Clare McManus \\ Manchester, United Kingdom \\ Dr Andrea Giraldez-Hayes \\ University of East London
}

\begin{abstract}
Coaching supervision is still an emergent profession with a limited body of research to support its credibility and practice. This qualitative study is the first to explore the use of music and mark-making as a creative tool within coaching supervision and highlights information about both coach and coach supervisor experience. The research explores the question, 'How does using mark-making in response to music within coaching supervision affect coaches' experience of reflective practice?' through semi-structured interviews, analysed using Interpretative Phenomenological Analysis (IPA) methodology. Findings revealed that using music and mark-making as a creative tool within coaching supervision enhances reflective practice and supports the client-supervisor relationship, enabling highly effective supervision to take place. The results offer coaches, coaching supervisors, coach educators and researchers and other professionals in other contexts where supervision forms an integral part of professional support and development insights into using music and other creative tools in supervision sessions and the impact on reflective practice.
\end{abstract}

Keywords: coaching supervision, music, creativity, coaching psychology, reflective practice

\section{Introduction}

Perceptions of the practice and process of coaching supervision are shifting. During the last decade, coaching supervision has grown in many areas, evidenced by the volume of training programmes specifically for coaching supervision, the publication of several key books and chapters, and the 
development of accreditations within prominent coaching bodies (Hawkins and Turner, 2017). A recently published document, the Manifesto for Supervision (Hawkins et al., 2019) is described as a "call to arms" (p. 2), detailing why coaching supervision is essential for continuing personal and professional development. In a contemporary review of the literature, Bachkirova et al. (2020) note that "coaching supervision is emerging as a discipline in its own right" (p. 31), although they found limited evidence-based literature grounded in academic rigour due to practitioners, rather than academics and researchers, conducting the majority of published work to date.

The variety of coaching supervision models is vast, with many originating in psychotherapy or social work models and practices (Moyes, 2009). However, a review of these models reveals that the relationship between creativity and coaching supervision is still limited. Historically, creativity has been used and researched extensively in therapy (Martin et al., 2018; Pratt, 2004; Shafir et al., 2020) and to a lesser extent in coaching (e.g. Palus, 2006; Whitaker, 2010), with Tomlinson (2020) arguing that the use of imagination in coaching is an under-researched area. The literature on creativity in coaching supervision exists (e.g. Schuck, 2011; Seto and Geithner, 2018), but is very limited. Using creativity as an integrated part of the coaching process and, by extension, the coaching supervision process, is still an emergent field of exploration with much research focusing on coaching for creativity (Maisel, 2019). Curiosity around the role of creativity within the coaching process itself is gaining traction due to assertions around creativity's ability to support coaches and clients with new thinking and envisioning the kind of life they want to live (Fitzpatrick, 2014) and the potential for a creative space within coaching conversations to support client movement between conscious and unconscious states, akin to the creative process itself (Gash, 2016).

The relationship between reflective practice and coaching supervision is more entwined, with Carroll (2010) describing the role of supervisors as facilitators of reflection, in part realised through their setting up of an environment of inquiry to explore the supervisee's practice. Indeed, some organisations refer to coaching supervision as reflective practice (Hawkins and Schwenk, 2006), finding the need for an intentional practice of considered reflection essential for coach development (Passmore, 2011). Insight can also be drawn from experimental studies in the use of arts and creativity to enhance reflective practice, with Blanco et al. (2018) using film clips as prompts to frame reflective discussions with a particular focus on emotional experience, and Quinn (2019) using the drawing of mandalas as a metaphor for engagement and sharing within an external dialogue. 
This paper aims to open a dialogue between academics and practitioners within the coaching community around the role of creativity in coaching and coaching supervision and think more broadly about how creativity can inform and support reflective practice in coaching supervision.

Following an analysis and exploration of relevant, contemporary literature associated with coaching supervision; reflective practice within coach development; and the use of creative practice within coaching, therapy and other facilitated dialogues, details of how music and creative mark-making was integrated into coaching supervision for the purpose of this study will be outlined, alongside the rationale for their inclusion over other creative tools. An exploration of the suitability of interpretative phenomenological analysis (IPA) as the chosen methodology for this study will be presented, before key themes from participants' experiences of experimenting with creative mark-making in response to music during coaching supervision will be introduced. A discussion of these themes will highlight aspects of relevance, alongside limitations, implications and recommendations for future research.

\section{Literature review}

This section reviews relevant literature in creativity within a coaching supervision context, the role of reflection within coaching supervision and music and listening in facilitated dialogue and embodied response and creative mark-making.

\section{Coaching Supervision}

Palmer and Whybrow (2018) describe supervision's role as moving "from the periphery to becoming an essential and necessary element across the spectrum of coaching life and work" (p. 470), and indeed Michael Carroll (2018) is given an entire chapter in their book to explore coaching psychology supervision and emerging best practice. Thus, in what would appear to be a very short space of time, interest in coaching supervision has exponentially increased, although it remains best practice rather than mandatory (Bachkirova et al., 2011). Unfortunately, the literature has failed to catch up with this new level of attention, and coaching supervision remains a largely unregulated and fragmented profession (Diller et al., 2020; Schutte, 2019).

Hawkins and Schwenk (2006) outline three core functions of effective coaching supervision, suggesting its purpose as qualitative, developmental and resourcing. Within the developmental function, the authors outline how 
opportunities for the supervisee to reflect upon and explore their work with clients forms part of the process of skills and capabilities development, proposing that reflection within the context of coaching supervision enables coaches to understand their clients and their own reactions and responses.

\section{Reflective practice in coaching supervision}

Cox (2013) positions reflective practice within all three constituent spaces of her Experiential Coaching Cycle, noting pre-reflective experience, reflection on experience and post-reflective thinking as crucial elements of successful coaching. This model builds on the work of Schön (1991), who differentiated reflection-in-action, or almost immediate, in-the-moment reflection, from reflection-on-action, which happens post-event. The supervision process can be understood as an important opportunity for coaches to perform this reflectionon-action (Carroll, 2018). Passmore and McGoldrick (2020) found that reflection during coaching supervision allowed for the discovery of blind spots in the coaches' own reflections on practice, suggesting that the wider perspective that supervision allows can be truly transformational.

In addition to supporting coaches in developing a better understanding of themselves and their practice (Turner and Palmer, 2018), reflection within coaching supervision can build an understanding of the dynamics of the coachclient interaction (Hawkins and Schwenck, 2006), thus supporting part of the wider function of supervision to protect the supervisee's clients and hold their best interests as key goals within the process (Turner et al., 2018). James (2020) positions reflective acuity as an asset for coaches, providing a critical tool with which to examine their practice and, in combination with coaching supervision, one which provides opportunities to "maintain a coaching environment that is physically, ethically and psychologically safe" (p. 403).

De Haan (2017) suggests that with many coaches self-selecting supervisors, highly trusting and satisfactory relationships that allow challenging issues to be brought to supervision can be cultivated. Cox and Bachkirova (2020) further support this idea of supervision being founded on support and trust, suggesting that coaches dealing with difficult emotional situations within their coaching practice tend to use self-reflection or supervision, identifying self-reflection as the internal and coaching supervision as the external manifestation of this same functional analysis and exploration of their experience in practice. 


\section{Creativity in Coaching and Coaching Supervision}

Fuster's (2013) analogy of creativity as a "past memory transformed by imagination and projected to the future" (p. 125) resonates with facilitated dialogues, for what is coaching if not an opportunity to encourage the client to utilise creative foresight to explore optional and divergent pathways towards an emergent future? This positioning of creativity as a memory of the future is helpful when exploring the wider literature investigating how creative tools could be introduced into coaching supervision and reflective practicebecause a core function of supervision lies in supporting coaches to explore potential futures for both their practice and their clients.

Some contemporary papers seek to bring creative tools into the coaching process, for example Humphrey and Tomlinson (2020) looked at how poetry could be used within coaching to support and enable creativity, empathy, awareness, and emotional exploration. The literature gap remains in understanding how these creative tools can be introduced in coaching supervision to specifically support its role, which can be considered in part as the development of ethical and well-resourced coaches (Turner and Passmore, 2018).

Hill \& Lloyd (2015) examined the use of imagery as a tool for reflective practice, finding that beyond simply presenting an opportunity for a descriptive narrative, when individuals selected an image that resonated with their circumstances, the image itself could support a deep exploration and insight into specific situations faced by the viewer. Perhaps most strikingly, Hill and Lloyd (2015) found that the use of imagery can elicit emotional responses, supporting the belief that aesthetic forms can be successfully used as affective tools

\section{Music and the role of listening in facilitated dialogue}

There is a whole suite of fascinating research linking music and functions within the human brain and body. Hetland (2000) studied the impact of listening to music and increased spatial-temporal reasoning; Panksepp and Bernatzky (2002) investigated links between music and behaviour change; and Lynar et al. (2017) explored the emotional and physiological responses of listening to music, finding that music-listening has a great potential to enhance both quality of life and wellbeing. 
Much of the research into music as a tool within facilitated dialogue comes from explorations of therapeutic relationships. Frohe-Hagemann et al. (2015) describe the receptive method of intentional listening to music within therapeutic approaches as a tool for both relaxation and reduction of pain and anxiety. Frohe-Hagemann et al. (2015) specifically outline the Bonny Method of Guided Imagery and Music (GIM), where music is used to stimulate an experiential client discourse about the imagery and accompanying emotions that the client experiences whilst listening to music. Clients are first invited to enter a deeply relaxed state, leading to an altered state of consciousness. The processing stage of the Bonny Method of GIM allows the client to re-join an ordinary state of consciousness, integrating the music and image experiences through a drawn mandala, or other drawn manifestation, to capture the imagery or emotion expressed (Bruscia and Grocke, 2002; Ventre, 2002). Lawes (2017) describes the music within GIM as a container for the client's experience, enabling them to discover inner resources and find solutions to problems.

There is a body of emerging research (e.g. Cake et al., 2015; Guillaumier, 2016) exploring the use of music and other creative practices as opportunities for narrative making and critical reflection. However, the current literature focuses on the use of creative reflection from an individual perspective, rather than exploring these ideas in dialogic spaces. Work linking creativity and sense-making, wellbeing and enhanced emotional expression (e.g. Croom, 2011; Puig et al., 2006) demonstrates links between artistic stimuli and powerful human experiences, with Lomas (2016) taking this one step further and positioning positive art as an emergent field that links artistic expression and appreciation of visual art, music, literature and drama with positive outcomes such as enriched experience, sense-making and bonding.

\section{Embodied response and creative mark-making}

As with research linking music and emotional response, similar studies have investigated how we emotionally respond to art (Cheung et al., 2019; Hill and Lloyd, 2015; Silvia, 2005). Kalita (2020) explored the use of Pauline Oliveros' Deep Listening concept (Oliveros, 1974) within therapeutic relationships and speaks of the need for a "continuous, fluent flow" (p. 291) between the body and mind when drawing attention to nonverbal register, or communication outside of language. Oliveros' original vision for Deep Listening was that it would allow for heightened states of awareness or "expanded consciousness" (p. 2), with music described as a by-product of her sonic meditations. 
Matte-Blanco (1988) developed a model to explain two distinct ways of paying attention: symmetric, connected with our unconscious emotions, and asymmetric, connected with thinking and cognition. Herein lies an opportunity for creativity to be utilised within coaching supervision sessions to support subconscious processing and to help coaches transition from thinking into feeling spaces for reflection. Mehta et al. (2019) talk about creativity as an embodied endeavour, something that "happens in all bodies and materialities, not just from the neck up inside the head", (p. 7). Using creative mark-making as an expressive response to music is one way to bring the coach's attention to their bodily and emotional responses to a line of inquiry, rather than strictly interrogating their thinking around, and cognitive processing of, recent events in their coaching practice.

McIntosh (2010) discusses how for those who do not perceive themselves as creative, engaging in the act of creativity can be rewarding. Of particular interest is his assertion that in order to engage in creative acts, it is imperative to separate artistic talent from creativity, and to then acquire and utilise our creative energy. By using the terminology creative mark-making rather than drawing or illustrating, and by designing this abstract creative output as a process, rather than an outcome, it is hoped that coaches who do not perceive themselves to be artistic, or who perhaps experience barriers around their own relationship to creativity, will feel safe to participate in the method with minimal risk of self-criticism or judgment getting in the way.

Han (2016) linked drawing to music with both a physical representation of an individual's cognitive and affective responses to the music, and as an opportunity for an individual to represent and express their listening experience. Although creative mark-making in response to music is not automatic drawing in its purest form, that is drawings that are produced under a dissociated state, Maclagan (2013) describes the intentionality of creating marks in an automatic way as displaced, suggesting "it is not the artist who draws, but something outside their normal responsibility", (p. 185). A similar disconnection from intentionality is perhaps achievable when the marks are in response to music, with eyes closed or the gaze detached from the unfolding imagery.

\section{The Current Research}

The potential for music and creative mark-making to enhance reflective practice makes an exploration into introducing such creative tools within the coaching supervision process intriguing. There is somewhat limited research into coaching supervision as a discipline, with Bachkirova et al.'s (2020) 
inclusion criteria identifying only 68 papers for analysis. The sole review on coaching supervision literature published previously largely borrowed research from other disciplines (Moyes, 2009). Coupled with the wide-ranging debate over what the definition of coaching supervision should be (Passmore, 2011; Tkach and DiGirolamo, 2017), this creates an opportunity for the current study to support the development of research into coaching supervision and its function overall, whilst adding to the emergent clarity on the benefits of supervision to coaches as an integral and valuable part of their professional practice. This research comes at a time where professionalisation in the field of coaching is increasingly important, solidifying this as an area of research that is both contemporary and pertinent.

The current study contributes to the knowledge of how introducing creativity into coaching supervision can support reflective practice by exploring the use of music and creative mark-making to aid reflection during coaching supervision and examining the experiences of both coaches and coaching supervisors. The study positions reflection as an integral and essential part of coaching development and introduces creative practice into the coach/coach supervisor relationship and the coaching supervision process itself. It explores the key question: How does using mark-making in response to music within coaching supervision affect coaches' experience of reflective practice? For the purpose of the study, creative mark-making means using pens, pencils or crayons to create dots, lines, marks, patterns and textures; reflection can be understood as "purposeful focusing on thoughts, feelings, sensations and behaviour in order to make meaning from those fragments of experience" (Voller, 2010 p. 21); coaching is defined as a "facilitated, dialogic, reflective learning process" (Cox, 2013, p. 1); and coaching supervision as "the process of professional support which ensures continuing development of the coach and effectiveness of his/her coaching practice through interactive reflection, interpretative evaluation and the sharing of expertise" (Bachkirova, 2008, pp.16 $-17)$.

\section{Methodology}

A qualitative research methodology was chosen as the intention was to understand the experience of both coaching supervisors and coaches in bringing creativity into coaching supervision. This research takes a phenomenological, epistemological position focusing on the experience of coaching supervisors and coaches using music and mark-making within a coaching supervision session. Interpretative Phenomenological Analysis (IPA) (Smith et al., 2009) was used to analyse semi-structured interviews conducted with both coaching 
supervisor and coach participants. IPA was chosen due the subjective and contextual nature of coaching supervision and its suitability for hermeneutical and ideographical research, due in part to its position as a social activity, as positioned by Rajasinghe (2020) in his exploration of IPA in coaching research. Utilising IPA allowed for the researcher to build an understanding of both the supervisor and coach experience of using music and mark-making in coaching supervision.

A purposive sample of three coaching supervisors and three coaches was recruited. All participants identified as women and were English-speaking, ranging in age from 35-74. All coaching supervision participants had at least two years' experience as a coaching supervisor and held or were working towards professional accreditation at the time of their participation. All coaching participants held or were working towards professional accreditation at the time of their participation.

The study was conducted with approval from the University of East London in line with the School of Psychology's Code of Practice for Research Ethics, and the British Psychological Society's Code of Ethics and Conduct. Each transcript was pseudonymised and analysed individually, in line with the idiographic nature of IPA.

\section{The Coaching Supervision}

Each participant was provided with a participant information sheet appropriate to their role in the process as either coach or coaching supervisor which detailed the rationale, time commitment and outline for the study. All participants were invited to a briefing call with the researcher, and a subsequent training session was held for the coaching supervisor participants to outline the creative exercise and to aid with the technical delivery of this exercise via MS Teams. A PDF detailing the exercise was provided in advance of the coaching supervision sessions and supervisors were invited to set up and contract the session in their own style, with the exercise itself the only prescriptive element of each supervision session.

Each coaching supervisor was matched with a coach in line with their availability and meetings were set up by the researcher via MS Teams. After completion of the coaching supervision sessions, each participant was invited to a 45-60-minute semi-structured audio-recorded interview with the researcher which took place within 10 days of the coaching supervision. 


\section{Results}

Three overarching themes emerged from the data. These were labelled as: 1) Mark-making to music as a catalyst for flow, 2) Movement as a doorway to the unconscious mind, and 3) Creativity surfacing new perspectives. The first and third topic focus on the inner experience and the qualities that emerged from the creative exercise. The second topic focuses on the external experience of the coach and supervisor. The main themes and their corresponding subthemes are shown in Table 1.

Table 1: Main themes, sub-themes and participant prevalence

\begin{tabular}{|c|c|c|c|c|}
\hline Main themes & Sub-themes & $\begin{array}{c}\text { Coach } \\
\text { Prevalence }\end{array}$ & $\begin{array}{l}\text { Supervisor } \\
\text { Prevalence }\end{array}$ & $\begin{array}{c}\text { Overall } \\
\text { Prevalence }\end{array}$ \\
\hline \multirow{3}{*}{$\begin{array}{l}\text { 1.0 Mark-making } \\
\text { to music as } \\
\text { a catalyst for } \\
\text { flow }\end{array}$} & $\begin{array}{l}1.1 \text { Becoming } \\
\text { present }\end{array}$ & 3 & 2 & 5 \\
\hline & $\begin{array}{l}\text { 1.2 Intense focus } \\
\text { on the music }\end{array}$ & 3 & 3 & 6 \\
\hline & $\begin{array}{l}\text { 1.3 The emergence } \\
\text { of clarity }\end{array}$ & 3 & 3 & 6 \\
\hline \multirow{3}{*}{$\begin{array}{l}\text { 2.0 Movement as } \\
\text { a doorway } \\
\text { to the } \\
\text { unconscious } \\
\text { mind }\end{array}$} & $\begin{array}{l}\text { 2.1 Using the } \\
\text { hands to get } \\
\text { out of the mind }\end{array}$ & 3 & 2 & 5 \\
\hline & $\begin{array}{l}2.2 \text { Movement as } \\
\text { connection to } \\
\text { self and others }\end{array}$ & 2 & 2 & 4 \\
\hline & $\begin{array}{l}\text { 2.3 Mark-making } \\
\text { as unconscious } \\
\text { processing }\end{array}$ & 2 & 3 & 5 \\
\hline \multirow{3}{*}{$\begin{array}{l}\text { 3.0 Creativity } \\
\text { surfacing } \\
\text { new } \\
\text { perspectives }\end{array}$} & $\begin{array}{l}\text { 3.1 Creating the } \\
\text { conditions for } \\
\text { deep reflection }\end{array}$ & 2 & 2 & 4 \\
\hline & $\begin{array}{l}\text { 3.2 Freedom from } \\
\text { the thinking } \\
\text { mind }\end{array}$ & 2 & 2 & 4 \\
\hline & $\begin{array}{l}\text { 3.3 The emergence } \\
\text { of clarity }\end{array}$ & 3 & 3 & 6 \\
\hline
\end{tabular}




\section{Mark-Making to Music as a Catalyst for Flow}

There was a clear sense that mark-making in response to music had allowed the coach participants to become present in the moment and this, in turn, had allowed clarity to emerge post-activity. All coach participants pointed out how the mark-making had acted as a tool to aid focus on the music, and this was also observed by the supervisors.

\subsection{Becoming present}

All coach participants noted that the mark-making led to a felt sense of being present and this total immersion in the exercise itself was also remarked upon by the supervisors, with Sally describing her observations as follows:

I was thinking about how in flow she was ... she kind of had her head back. And she was doing a bit erm, you know like Stevie Wonder when he's singing and he's so into the music and his eyes are closed and he's just like absolutely entranced. (Sally)

One coach, Shelley, chose to complete the exercise with their camera off and their supervisor did not remark on their sense of presence. Shelley noted that she had continued to reflect on the mark-making after the supervision session, concluding:

I thought it's an amazing way of bringing you to be present erm probably a lot more powerful than meditation, in my mind, or in my case. (Shelley)

\subsection{Intense focus on the music}

All participants commented on the level of focus that the mark-making had brought to the music. Hannah remarked that the mark-making allowed her to concentrate despite a diagnosis of ADD:

I was totally immersed in the music ... my concentration because I've got ADD, my concentration was not wandering. I was totally focused. (Hannah)

Ainsley was struck by the ease with which the mark-making had allowed her to focus on the music during the supervision session:

I've always struggled with meditation. The kind of bringing your mind back and not just kind of let it wander to all of the future stuff and the things that you've got going on ... I found that the combination of the music and the mark-making just really helped me to focus on the music, listen to the music. (Ainsley) 


\subsection{The emergence of clarity}

The mark-making to music gave the coaches greater clarity on their supervision topics and appeared to allow them to access a different level of understanding of what was showing up for them. Sally, in particular, noted a shift in her coach's framing from before to after the exercise, reflecting:

... she said at the beginning, "I want to think about some specific skills I need to change in my approach" ... when she came back after listening to the music, it had moved into "I want to be honest with him." (Sally)

\section{Movement as a doorway to the unconscious mind}

Mark-making provided an invitation for the coaches to move out of stillness and into their body, something which they all considered an important part of their experience.

\subsection{Using the hands to get out of the mind}

The physicality of using the hands to respond to the music through markmaking led to a sense of moving away from cognition and the body taking over from the thinking brain. Shelley considered the way the mark-making was an expression of her experience:

... somebody, which it wasn't me or my mind doing it ... is expressing something ... and yes it's my hand, but I guess there's something that I ... can't control that is just telling, moving me ... and I think that is quite magic. (Shelley).

Using mark-making to focus on the music led to all coaches remarking on the physical process, and the supervisors noted the impact of this movement on the level of focus they observed in their coaches. Sally questioned if the movement shifted the act of listening to music away from being a cognitive process.

... there was a physicality about it where her body...was starting to do something with the music. She was definitely feeling it ... I think there's something about doing both that helped her just become really absorbed in it...I wonder if it's more...cognitive if you're just listening to it ... there was just something about the physical task as well as the listening task. (Sally)

\subsection{Movement as connection to self and others}

Movement and the physicality of mark-making was universally experienced in all supervision sessions. All coach participants remarked on the 
way in which the mark-making specifically had allowed them to feel a deeper sense of connection to themselves. Shelley felt that the mark-making had allowed her to connect with her inner child:

I think that's what I felt ... I'm doing some work on ... connecting with my inner child ... and it felt that I was doing that. It felt as if I was aligning myself with that small Shelley. (Shelley).

The movement within the sessions also led to connections between coach and supervisor, with two supervisors noticing that they had been unconsciously swaying to the music during the session. Perhaps more remarkably, they realised they were unintentionally swaying in time with their coaches. Despite not liking the music chosen, Caroline remarked on this shared movement, saying:

I noticed myself swaying to the music ... and that kind of caught me off guard because I really was flowing with the music ... like you would if you were in a German beer garden....and then as I glanced at the screen, I see Hannah doing exactly the same $[. .$.$] we were absolutely in sync. (Caroline)$

In Shelley's supervision session, she decided to complete the markmaking to music with her camera switched off. Her supervisor, Nancy, remarked on the way swaying brought them back to connection and a sense of reflecting together following a sense of disconnection that she had experienced from the camera turning off:

I sort of found myself doing this a little bit with the music [swaying]. And the first thing the client said was, "I found myself doing this with the music" [swaying] and I was like [gasp] "we're joined!" ... that moment of disconnection was like dropping a pebble and rippling and then as we both connected with the music it was that sort of ability to reflect again, that sort of clear surface looking to reflect again. (Nancy)

\subsection{Automatic drawing as unconscious processing}

All coaches chose to complete the mark-making with their eyes closed and remarked on experiencing the mark-making as an automatic process, happening without the need to bring attention to the mark-making itself. Ainsley talked about her experience:

.. the mark-making ... it was just happening. (Ainsley)

And later: 
I don't know if I even thought about how it would look if I'm honest I just wasn't focused on anything apart from ... the music. I think in my head I thought it was this kind of big piece and it was quite small [laughter] ... in the middle of the paper I'd say that was like a surprise when I looked. (Ainsley)

In another supervision session, this unconscious process and a similar discrepancy between the imagined output from mark-making and the reality of the marks on the paper was commented on by supervisor Caroline:

I don't think she was in a conscious way of making marks on the paper ... at that point when she was journaling, she noticed she hadn't used up all the paper. (Caroline)

\section{Creativity surfacing new perspectives}

There was a universal experience during the supervision sessions of the creative exercise allowing the coach to access a different point of view, often from within themselves.

\subsection{Creating the conditions for deep reflection}

All coach and supervisor pairs met for the first time whilst taking part in this research. The lack of relationship did not present a barrier for the coaches doing deep reflective work or leaving the session with new thinking. Sally reflected on the way the mark-making to music had presented an interlude that fostered connection between coach and supervisor:

I reflected afterwards ... how very open the coach had been to say that we hadn't met ... I've written in my post-session ... "the conversation afterwards was flowing and open, it felt like the musical interlude had validated us being together as much as doing something specific" ... that kind of being in something together, unhurried, reflective ... That really emphasised the quality of the work we did together. (Sally)

Nancy also remarked on the sense of connection and the coach's takeaway from the session being meaningful despite the limited time spent together and having never worked together before:

The client talked about being excited ... at the end ... "what are you taking with you and what next?" was "excited and I know what to do now." So that wasn't nothing was it? Especially seeing as we'd only met once and really our time was spent contracting....we maybe had 15 minutes left at the end. I think ... that's really noteworthy. (Nancy) 


\subsection{Freedom from the thinking mind}

The creative combination of music and mark-making allowed participants to still the thinking mind, with Shelley identifying a shift in her present moment experience during the exercise:

I think that's why it was so special ... because it really felt I could leave my brain or my thinking brain ... outside ... it brought me really present ... it connected me with my body, with my intuition or with the flow. (Shelley)

\subsection{The emergence of clarity}

There was a shared language about the creative exercise being freeing and allowing clarity to emerge for the coaches both in terms of their topic and the way they wanted to move things forward post-supervision. Sally noticed a shift in her coach's dialogue following the music:

... there was a definite sort of fluidity afterwards ... the topic that she had brought up at the beginning ... I think she really really wanted to get on with it ... maybe something had happened to her in her reflections as she was listening to the music, to bring that even further up to the surface. (Sally)

Even where the coaches were less clear on their topic or question, the mark-making to music appeared to allow space for clarity to emerge. Hannah described the emergence of her topic for the supervision session through completing the creative exercise:

.. I got so involved in it ... that was totally and utterly freeing ... It was illuminating. Because I had come to supervision not really knowing what I was going to talk about ... and we got to the stage where I said, "well I don't really know what I'm going to coach in"... So that's what we talked about. And some interesting things definitely came out of that for food for thought for me. (Hannah)

\section{Discussion}

The purpose of this study was to investigate both coaches' and coaching supervisors' experiences of experimenting with creative mark-making in response to music during coaching supervision, with a particular focus on the impact on reflective practice. The study is one of the first to explore the use of music and creative tools during coaching supervision, and the findings indicate several ways in which the creative exercise supported and enhanced the reflection taking place. The key result of this work was that music and markmaking can support coaches to perform deep reflection-on-action (Schön, 1991) during coaching supervision, allowing them to access fresh perspectives on 
their topic or question. Participants reported a sense of focus and flow which in turn allowed clarity to surface during dialogue with the supervisor post-activity. These key findings are reflected in the three key themes that emerged within the current study.

One of these key themes was the idea that mark-making to music acted as a catalyst for flow, or "complete absorption in what one does" (Nakamura and Csikszentmihalyi, 2014, p. 239). As with music used during therapeutic approaches such as GIM (Lawes, 2017), the findings of the current study suggest that participants were able to enter an altered state of consciousness during the music and mark-making activity, allowing them to access inner resources and identify new perspectives from which to consider their questions. The intense focus on the music that the mark-making facilitated allowed coaches to feel present and several participants mentioned being in or observing a state of flow, in keeping with research into the relationship between musiclistening and flow (e.g. Chiricoo et al., 2015; Loepthien \& Leipold, 2021).

The idea that being in flow is a useful state for coaches and within coaching supervision has received some prior attention (e.g. Kimblin, 2009; Arnold, 2014). However, the idea that creative tools could invoke this state of intense engagement and lack of self-consciousness has not previously been examined within the coaching supervision context. The emergence of flow within the supervision sessions allowed the participants to move from their thinking minds and into their bodies. Despite supervision's typical positioning as a dialogic endeavour, existing research into using embodied practice during supervision through bringing concepts such as mindfulness into the process (Levitt, 2016) highlights the existing relationship between flow and positive supervision outcomes. The current study builds on these concepts, highlighting the enormous potential of bringing creativity into reflective supervision as a catalyst for flow and focus.

Another theme in the study is the way in which movement seemed to facilitate a shift into the unconscious mind. Of particular note is the experience of moving the hands to make marks taking participants into their bodies and out of their minds. The mark-making appeared to manifest as a bodily response to the music, with participants reporting that this process occurred outside of their cognition, a finding in line with Mehta et al.'s (2019) positioning of creativity as an embodied endeavour. One unexpected outcome from the supervision sessions was the connection that was built between supervisor and coach, particularly considering each pair had never worked together before and were meeting online. The physical connection where both supervisor and coach 
swayed in time to both the music and each other presents not just synchronicity but an example of communication between participants on the outside of language and expanded consciousness described in Pauline Oliveros' Deep Listening framework (Oliveros, 1974). This finding also suggests that the embodied listening became a means of relational connection alongside providing a means for the coach to connect to the self.

The final theme of creativity allowing new perspectives to surface focused on the shift in the coach's thinking post-creative exercise. For all coaches, using a creative tool allowed them to access fresh perspectives and clarity on their chosen topic or question and this clarity was also remarked upon by all three supervisors. This finding supports the idea of creativity as a memory of the future (Fuster, 2013) where participants were able to access perspectives from imagined future possibilities and scenarios that had previously been hidden in their unconscious experience. The separation of the thinking mind and the emergence of clarity were universal themes across the supervision sessions, suggesting that using a creative tool surfaced information and thinking that was unavailable or difficult to access through dialogue alone.

Although the marks were not explored or examined directly during the ensuing dialogue, the way in which coaches described their mark-making as occurring outside of their cognition supports the literature around automatic drawing as a displaced experience where the artist, or in this case the coach, is not the one making the marks (Maclaglan, 2013). The imagery itself could form an important tool for reflective practice in itself, with all of the coaches describing their marks and suggesting the ongoing reflection that took place beyond the supervision session itself was informed by the whole process, not just the focus on the music. Further explorations of the marks themselves could offer an opportunity to investigate whether the output captures any of the emotion or processing experienced during the exercise, offering an additional stimulus for contemplation or shared dialogue.

Finally, the research supports Lomas' (2016) concept of positive art as a catalyst for enriched experience, sense-making and bonding, with all three outcomes visible in the data and subsequent themes to emerge from analysis. Music and mark-making can be understood in this context as a stimulus for clarity and sense-making of the supervision topic and as an important component in the development of the connection between coach and supervisor, regardless of their level of previous interaction or knowledge of one another. 


\section{Limitations and recommendations for future research}

The following limitations should be considered when considering the emergent themes and conclusions from this study. IPA studies require an acknowledgement of the researcher as an active agent in the generation of meaning. The researcher's personal biases and understanding of the topics explored may have led to a narrower focus during interpretation than might have otherwise been possible. Explorations of the coaching supervisors' prior experience and approach to supervision were not included as part of this study, although an exploration of their experience and practice did form part of the semi-structured interviews with the researcher. The coaching supervisor's style may have played an active role in the experience of the coaches and subsequently in the findings.

The supervision was conducted online which may have impacted on the overall experience for both parties, and the nature of the supervision sessions taking place as one-off blind supervision where no existing relationship or trust had been built between coach and supervisor undoubtedly impacted on the overall experience for participants.

Finally, the piece of music used in the creative exercise was chosen by the researcher and it is important to note that other pieces of music may have elicited different responses in both coaches and supervisors. An exploration of the impact of music on emotions would allow for valuable insights into the potential role that the style of music chosen could play in the experience and outcomes.

\section{Conclusion}

Coaching supervision is still an emergent profession with a small body of research to support its credibility and practice. This qualitative study is the first to explore using music and mark-making in coaching supervision and highlights information about coach and coach supervisor experience of using a creative methodology within a supervision session.

The research indicates that there are significant benefits to using music and mark-making within coaching supervision, particularly for coaches and supervisors who seek to build focus and achieve clarity as part of the supervision process. These promising findings will be of interest to coaches, coaching supervisors, coach educators and researchers, alongside other professions where supervision forms an integral part of professional support 
and development, who can build on these findings to explore the use of creative tools in their practice.

The findings show that mark-making to music can provide a powerful interlude within the coaching supervision session, allowing the coach to build focus and become present in the self and the body. The participant accounts presented suggest that the use of creative tools in supervision has considerable potential as an innovative method that enhances reflective practice and supports the client-supervisor relationship, enabling highly effective supervision to take place. 


\section{References}

Arnold, J. (2014). Coaching Supervision at its BEST. Crown House Publishing. Bachkirova, T. (2008). Coaching supervision: reflection on changes and challenges. People and Organisations at Work, Autumn Edition.

Bachkirova, T., Jackson, P., Hennig, C., \& Moral, M. (2020). Supervision in coaching: Systematic literature review. International Coaching Psychology Review, 15(2), 31-53.

Bachkirova, T., Jackson, P., \& Clutterbuck, D. (2011). Coaching and Mentoring Supervision: Theory and Practice: The complete guide to best practice. McGraw Hill Education.Blasco, P.G., Moreto, G., \& Pessini, L. (2018). Using movie clips to promote reflective practice: A creative approach for teaching ethics. Asian Bioethics Review, 10(1), 7585. https://doi.org/10.1007/s41649-018-0046-z

Cake, S.A., Solomon, L., McLay, G., O’Sullivan, K., \& Schumacher, C.R. (2015). Narrative as a tool for critical reflective practice in the creative industries. Reflective Practice: International and Multidisciplinary Perspectives, 16(4), 472-486. https://doi.org/10.1080/14623943.2015.1064384

Carroll, M. (2010). Supervision: Critical reflection for transformational learning (Part 2). Clinical Supervisor, 29(1), 1-19. https://doi.org/10.1080/07325221003730301

Carroll, M. (2018). Coaching psychology supervision. In S. Palmer \& J.A. Whybrow (Eds.), Handbook of Coaching Psychology: A guide for practitioners. (2nd ed., pp. 562-572). Routledge.

Cheung, M.C., Law, D., Yip, J., \& Wong, C.W. (2019). Emotional responses to visual art and commercial stimuli: implications for creativity and aesthetics. Frontiers in psychology, 10(14). https://doi.org/10.3389/fpsyg.2019.00014

Chirico, A., Serino, S., Cipresso, P., Gaggiolo, A., \& Riva, G. (2015). When music "flows". State and trait in musical performance, composition and listening: A systematic review. Frontiers in Psychology, 6, 906. https://doi.org/10.3389/fpsyg.2015.00906

Conner, T.S., DeYoung, C.G., \& Silva, P.J. (2016). Everyday creative activity as a path to flourishing. The Journal of Positive Psychology, 13(2), 181189. https://doi.org/10.1080/17439760.2016.1257049

Cox, E. (2013). Coaching Understood: A pragmatic inquiry into the coaching process. SAGE Publications Ltd.

Cox. E., \& Bachkirova, T. (2020). Coaching with emotion: How coaches deal with difficult emotional situations. Coaching Researched: A Coaching 
Psychology Reader, 167-181.

https://doi.org/10/1002/9781119656913.ch9

Croom, A.M. (2012). Music, neuroscience, and the psychology of wellbeing: A précis. Frontiers in Psychology, 2, 393. https://doi.org/10.3389/fpsyg.2011.00393

Diller, S.J., Passmore, J., Brown, H.J., Greif, S., \& Jonas, E. (2020). Become the best coach you can be: the role of coach training and coaching experience in workplace coaching quality and quality control.

Organisationsberatung, Supervision, Coaching, 27(3), 313-333. https://doi.org/10.1007/s11613-020-00662-8

Duffy, M., \& Passmore, J. (2010). Ethics in Coaching: An ethical decision making framework for coaching psychologists. International Coaching Psychology Review, 5(2), 140-151.

Fitzpatrick, L. (2014). The Cycle of Creativity: Gestalt coaching and the creative process. Gestalt Review, 18(2), 161-171. https://doi.org/10.5325/gestaltreview.18.2.0161

Frohe-Hagemann, I., Warja, M., Pedersen, I.N., Hall, A., McKinney, C., West, T.M., ... \& Goldberg, F.S. (2015). Guided imagery \& music (GIM) and music imagery methods for individual and group therapy. Jessica Kingsley Publishers.

Fuster, J.M. (2013). The Neuroscience of Freedom and Creativity: Our predictive brain. Cambridge University Press.

Gash, J. (2016). Coaching Creativity: Transforming your practice. Routledge.

Guillaumier, C. (2016). Reflection as creative process: Perspectives, challenges and practice. Arts and Humanities in Higher Education, 15(3-4), 353363. https://doi.org/10.1177/1474022216647381

Han, Y.J. (2016). Expanding music listening experience through drawing. General Music Today, 29(3), 12-18. https://doi.org/10.1177/1048371315622005

Hawkins, P., \& Schwenk, G. (2006). Coaching supervision: Maximising the potential of coaching. London: Chartered Institute of Personnel and Development.

Hawkins, P., \& Turner, E. (2017). The rise of coaching supervision 2006-2014. Coaching: An international journal of theory, research and practice, 10(2), 102-114. https://doi.org/10.1080/17521882.2016.1266002

Hawkins, P., Turner, E., \& Passmore, J. (2019). The Manifesto for Supervision. Henley Business School and the Association for Coaching. https://www.associationforcoaching.com/resource/resmgr/home/manifes to_for_supervision_20.pdf 
Hetland, L. (2000). Listening to Music Enhances Spatial-Temporal Reasoning: Evidence for the "Mozart Effect". Journal of Aesthetic Education, 34(3/4), 105-148. https://doi.org/10.2307/3333640

Hill, G., \& Lloyd, C. (2015). A practice-led inquiry into the use of still images as a tool for reflective practice and organisational inquiry. International Journal of Professional Management, 10(2). http://www.ipmajournal.com

Humphrey, D., \& Tomlinson, C. (2020). Creating Fertile Voids: The use of poetry in developmental coaching. Philosophy of Coaching: An International Journal, 5(2), 5-17. http://dx.doi.org/10.22316/poc/05.2.02

James, A. (2020). Reflective Practice in Coaching. In J. Passmore, (Ed.). The Coaches' Handbook (pp. 403-413). Routledge.

Kalita, L. (2020). Deep Listening: Explorations on the musical edge of therapeutic dialogue. Psychoanalytic Psychology, 37(4), 282. https://doi.org/10.1037/pap0000285

Kimblin, A. (2009). The Inner Game of Coaching. International Journal of Evidence Based Coaching \& Mentoring, 3, 38-50. http://www.business.brookes.ac.uk/research/areas/coaching\&mentoring/

Lawes. M. (2017). Music as dynamic experience of unfolding wholeness in Guided Imagery and Music (GIM): A psychoanalytic, musical, transpersonal and trans-scientific paradigm. An Interdisciplinary Journal of Music Therapy, Special Issue 9(2), 275-299.

Levitt, O. (2016). Mindfulness: Bringing body and breath to supervision. In J. Bownas, \& G. Fredman, (Eds.). (2016). Working With Embodiment in Supervision: A systematic approach (pp. 131-146). Routledge.

Lopethien, T., \& Leipold, B. (2021). Flow in music performance and musiclistening: Differences in intensity, predictors, and the relationship between flow and subjective well-being. Psychology of Music, 0305735620982056. https://doi.org/10/1177/0305735620982056

Lomas, T. (2016). Positive art: Artistic expression and appreciation as an exemplary vehicle for flourishing. Review of General Psychology, 20(2), 171-182. https://doi.org/10.1037/gpr0000073

Lynar, E., Cvejic, E., Scubert, E., \& Vollmer-Conna, U. (2017). The joy of heartfelt music: An examination of emotional and physiological responses. International Journal of Psychophysiology, 120, 118-125. https://doi.org/10.1016/j.ijpsycho.2017.07.012

Maclagan, D. (2013). Line Let Loose: Scribbling, doodling and automatic drawing. Reaktion Books. 
Maisel, E. (Ed.). (2019). Inside Creativity Coaching: 40 inspiring case studies from around the world. Routledge.

Martin, L., Oepen, R., Bauer, K., Nottensteiner, A., Mergheim, K., Gruber, H., \& Koch, S.C. (2018). Creative arts interventions for stress management and prevention - a systematic review. Behavioural Sciences, 8(2), 28. https://doi.org/10/3390/bs8020028

Matte-Blanco, I. (1988). Thinking, Feeling, and Being. Routledge.

McIntosh, P. (2010). Action Research and Reflective Practice: Creative and visual methods to facilitate reflection and learning. Routledge.

Mehta, R., Henriksen, D., \& Deep-Play Research Group. (2019). An embodied, dialogic endeavour: Towards a posthumanizing approach to creativity with Dr. Kerry Chappell. TechTrends, 63(1), 6-12. https://doi.org/10.1007/s11528-018-0357-7

Moyes, B. (2009). Literature Review of Coaching Supervision. International Coaching Psychology Review, 4(2), 162-173.

Nakamura, J., \& Csikszentmihalyi, M. (2014). The Concept of Flow. In M. Csikszentmihalyi, Flow and the Foundations of Positive Psychology: The collected works of Mihaly Csikszentmihalyi (pp. 239-263). Springer. Oliveros, P. (1974). Sonic Meditations. Smith Publications.

Palmer, S., \& Whybrow, A. (Eds.). (2018). Handbook of Coaching Psychology: A guide for practitioners. Routledge.

Palus, C.J. (2006). Artful Coaching. In S. Ting \& P. Scisco (Eds.), The CCI Handbook of Coaching: A Guide for the Leader Coach (pp. 259-285). Jossey-Bass. Retrieved from https://www.researchgate.net/profile/Charles_Palus/publication/310402 188 Artful coaching/links/582c65b308ae138f1bfde311/Artfulcoaching.pdf

Panksepp, J., \& Bernatzky, G. (2000). Emotional Sounds and the Brain: The neuro-affective foundations of musical appreciation. Behavioural Processes, 60(2), 133-155. https://doi.org/10/1016/S03766357(02)00080-3

Passmore, J. (Ed.). (2011). Supervision in Coaching: Supervision, ethics and continuous professional development. Kogan Page Publishers.

Passmore, J., \& McGoldrick, S. (2020). Super-vision, Extra-vision, or Blind Faith? A Grounded Theory Study of the Efficacy of Coaching Supervision. In J. Passmore, \& D. Tee. (Eds.) Coaching Researched: A Coaching Psychology Reader for Practitioners and Researchers (pp. 145-165). John Wiley and Sons. 
Pratt, R.R. (2004). Art, dance, and music therapy. Physical Medicine and Rehabilitation Clinics of North America, 15, 827-842. https://doi.org/10.1016/j.pmr.2004.03.004

Puig, A., Lee, S.M., Goodwin, L., \& Sherrard, P.A. (2006). The efficacy of creative arts therapies to enhance emotional expression, spirituality, and psychological well-being of newly diagnosed Stage I and Stage II breast cancer patients: A preliminary study. The Arts in Psychotherapy, 33(3), 218-228. https://doi.org/10.1016/j.aip.2006.02.004

Quinn, K. (2019). Something is going to happen here: The use of mandala art in enhancing reflective practice. Advances in Nursing Science, 42(3), E1E19. https://doi.org/10.1097/ANS.0000000000000242

Rajasinghe, D. (2020). Interpretative phenomenological analysis (IPA) as a coaching research methodology. Coaching: An International Journal of Theory, Research and Practice, 13(2), 176-190. https://doi.org.uk/10.1080/17521882.2019.1694554

Schön, D.A. (1991). The Reflective Practitioner: How professionals think in action. Ashgate Publishing Ltd.

Schuck, C. (2011). Inspiring Creative Supervision. Jessica Kingsley Publishers.

Schutte, F. (2019). Business coaching: A hen with ducklings. South African Journal of Business Management, 50(1), 1-7. https://doi.org/10.4102/sajbm.v50i1.398

Seto, L. \& Geithner, T. (2018). Metaphor magic in coaching and coaching supervision. International Journal of Evidence Based Coaching and Mentoring, 16(2), 99-111. https://doi.org/10.24384/000562

Shafir, T., Orkibi, H., Baker, F.A., Gussak, D., \& Kaimal, G. (2020). The state of the are in creative arts therapies. Frontiers in psychology, 11, 68. https://doi.org/10.3389/fpsyg.2020.00068

Silvia, P.J. (2005). Emotional Responses to Art: From collation and arousal to cognition and emotion. Review of General Psychology, 9(4), 342-357. https://doi.org/10.1037/1089-2680.9.4.342

Smith, J.A., Flowers, P., \& Larkin, M. (2009). Interpretative Phenomenlogical Analysis: Theory, Method and Research. SAGE.

Tkach, J.T., \& DiGirolamo, J.A. (2017). The state and future of coaching supervision. International Coaching Psychology Review, 12(1), 49-63. https://doi.org/10.1002/9781119656913.ch2

Tomlinson, C. (2020). Using the Romantics to understand the imagination: A creative and original methodology for research into coaching. International Journal of Evidence Based Coaching \& Mentoring, S14, 132-142. https://doi.org/10.24384/rq4t-ny31 
Turner, E., \& Palmer, S. (Eds.). (2018). The heart of coaching supervision: Working with reflection and self-care. Routledge.

Turner, E., \& Passmore, J. (2018). Ethical dilemmas and tricky decisions: A global perspective of coaching supervisors' practices in coach ethical decision-making. International Journal of Evidenced Based Coaching and Mentoring, 16(1), 126-142. https://doi.org/10.24384/000473

Turner, T., Lucas, M., \& Whitaker, C. (2018). Peer supervision in coaching and mentoring: A versatile guide for reflective practice. Routledge.

Voller, E. (2010). Developing the understanding of reflective practice in counselling and psychotherapy. [Unpublished doctoral dissertation]. University of Middlesex.

Whitaker, V. (2010). Offering creative choices in mentoring and coaching. In D. Megginson \& D. Clutterbuck (Eds.), Further techniques for coaching and mentoring (pp. 100-116). Routledge.

\section{Acknowledgements}

I would like to first thank my research supervisor, Dr Andrea Giraldez-Hayes, for her constant support and encouragement. A huge thank you goes to my mum, Gwynneth, who has spent endless hours proofreading and championing this research. I owe a large debt of gratitude to my participants who have all inspired me in myriad ways. Finally, thank you to my fellow MAPPCP (Masters in Applied Positive Psychology and Coaching Psychology) students, particularly the other two legs of my wonderful triad. I couldn't have done it without you. 